\title{
Assistência Estudantil e Covid-19: um estudo nas Universidades Federais da Região Norte do Brasil
}

\section{Student Assistance and Covid-19: a study at Federal Universities in Northern Brazil}

Nathanni Marrelli Matos Mauricio ${ }^{1}$, Alex Pizzio ${ }^{2}$, Eder Gama da Silva ${ }^{3}$, Josilene Rodrigues ${ }^{4}$, Hayala Danielle da Silva Mesquita ${ }^{5}$

\section{RESUMO}

O objetivo da pesquisa foi verificar as ações de assistência estudantil desenvolvidas pelas universidades da região norte do Brasil durante a pandemia de Covid-19, no período de março a outubro de 2020. Para tanto, realizou-se uma pesquisa descritiva e documental, buscando informações nos portais das instituições que dessem visibilidade ao que foi oferecido aos estudantes. Os dados foram copilados por meio de notícias, editais, relatórios e pesquisas. Os resultados apontam que oito das universidades instituíram, de forma excepcional e temporária, o auxílio-alimentação emergencial em pecúnia, além de ofereceram um auxílio específico para moradia. Somente a UFT ofereceu auxílio específico para saúde. A Universidade Federal Rural da Amazônia, a Universidade Federal de Rondônia e Universidade Federal de Roraima ofereceram auxílio-transporte; sete universidades oferecem alguma bolsa em pecúnia e cinco das universidades lançaram editais relativos ao apoio pedagógico. Todas as universidades aderiram ao projeto do Governo Federal "Alunos Conectados" e ofereceram auxílio financeiro aos estudantes para aquisição de equipamentos eletrônicos. A Universidade Federal do Amazonas, a Universidade Federal Rural da Amazônia e a Universidade Federal de Rondônia ofereceram auxílio-creche e a Universidade Federal do Amazonas ofereceu auxílios para aquisição de material didático. A Universidade Federal do Oeste do Pará e a Universidade Federal do Tocantins lançaram editais para auxílios específicos para estudantes indígenas e quilombolas. E a Universidade Federal do Pará, Universidade Federal Rural da Amazônia, Universidade Federal do Sul e Sudeste do Pará e Universidade Federal do Tocantins lançaram editais com auxílios destinados a pessoas com deficiência.

Palavras-chave: Assistência Estudantil. Universidades Federais. Região Norte do Brasil. Covid-19.

\section{ABSTRACT}

The objective of the research was to verify the student assistance actions developed by universities in the northern region of Brazil during the Covid-19 pandemic, from March to October 2020. For this, a descriptive and documentary research was carried out, seeking information on the portals of institutions that give visibility to what was offered to students. The data were collected through news, notices, reports and research. The results show that eight of the universities, exceptionally and temporarily, instituted emergency food aid in cash, in addition to offering specific housing assistance. Only UFT offered specific health assistance. The Federal Rural University of the Amazon, the Federal University of Rondônia and the Federal University of Roraima offered transport assistance; seven universities offer some scholarship in cash and five of the universities have issued calls for proposals for educational support. All universities adhered to the Federal Government's project "Alunos Conectados" and offered financial assistance to students for the purchase of electronic equipment. The Federal University of Amazonas, the Federal Rural University of the Amazon and the Federal University of Rondônia offered childcare assistance and the Federal University of Amazonas offered assistance for the acquisition of educational material. The Federal University of the West of Pará and the Federal University of Tocantins have launched public notices for specific assistance for indigenous and quilombola students. And the Federal University of Pará, the Federal Rural University of the Amazon, the Federal University of the South and Southeast of Pará and the Federal University of Tocantins have issued public notices with aid for people with disabilities.

Keywords: Student Assistance. Federal Universities. Northern Brazil. Covid-19.
Mestra em Gestão de Políticas Públicas. Universidade Federal do Tocantins.

E-mail: nathanni@uft.edu.br

Doutor em Ciências Sociais. Universidade Federal Federal do Tocantins.

3 Mestre em Prestacão Jurisdicional e Direitos Humanos. Universidade Federal do Tocantins.

Especialista em Gestão de Processos Gerenciais. Instituto Federal do Tocantins.

${ }^{5}$ Especialista em Gestão Pública. Universidade

\section{o.}

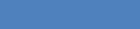




\section{INTRODUÇAOO}

De acordo com o art. 25 da Constituição Federal, "A educação, direito de todos e dever do Estado e da família, será promovida e incentivada com a colaboração da sociedade, visando ao pleno desenvolvimento da pessoa, seu preparo para o exercício da cidadania e sua qualificação para o trabalho", porém as desigualdades sociais trazem à tona que a educação de qualidade ainda não atinge toda a população. Segundo Rado \& Boneti (2009), parte da população em condições de vulnerabilidade enfrenta desafios para conseguir acessar a educação de qualidade e nela permanecer até a conclusão de seus estudos.

Ressalta-se que a educação é uma ferramenta essencial para transformar uma sociedade e que o fator educacional pode interferir na realidade social e econômica de um grupo que vive uma condição de visão imutável quanto a sua realidade para uma nova perspectiva de mutação promissora, assim, fazem-se necessárias a democratização e a equidade do ensino superior brasileiro (ARAÚJO, et al., 2011).

Segundo Faria (2015), a educação é a base de um país, influenciando todas as áreas da sociedade, tais como a política, a economia, a legislação e a moral de um povo. Além disso, é a melhor forma de resolver a maioria dos problemas de uma sociedade, sendo que o respeito a esse direito efetiva-se por meio do investimento nessa área, bem como a promoção de ações que visem o acesso universal ao conhecimento. $O$ mesmo autor afirma que a ampliação das oportunidades educacionais é considerada um dos fatores mais importantes para a redução das desigualdades sociais.

Nas duas últimas décadas, vivenciaram-se reformas educacionais que repercutiram nas taxas de matrículas e ampliaram a cobertura nos distintos níveis de ensino, logrando melhorias educacionais inegáveis, principalmente no que tange ao ensino superior. $A$ implementação de políticas de ampliação do acesso, como o aumento do número de vagas proporcionado pelo Programa de Apoio a Planos de Reestruturação e Expansão das Universidades Federais (REUNI) e a democratização da forma de ingresso, garantido pelo sistema de seleção implementado pelo Sistema de Seleção Unificada (SiSU), aliadas à política de investimentos recebidos com a criação do Plano Nacional de Assistência Estudantil (PNAES), transformaram as universidades federais física, econômica, social e culturalmente (BERALDO; MAURICIO; RODRIGUES, 2018).

Segundo Carvalho (2013), as políticas supracitadas acarretaram no significativo aumento do acesso ao ensino superior de parcela da população historicamente excluída, 
oriunda de famílias de baixa condição socioeconômica (CARVALHO, 2013). Assim, veio à tona a necessidade de garantia de condições para a manutenção destes estudantes na universidade, pois não basta só assegurar o acesso, é preciso buscar meios que auxiliem na permanência e na conclusão (BAQUEIRO, 2015).

De acordo com Kowalski (2012), apenas o acesso à educação superior gratuita não é suficiente para que estudantes em condições socioeconômicas desfavoráveis cursem a graduação. Muitas vezes, apesar da aprovação nas concorridas seleções das universidades federais, muitos estudantes têm que abandonar a oportunidade de concluir os cursos de graduação devido às dificuldades sociais e financeiras e, dessa forma, deixam de ter condições para galgar posição profissional qualificada.

Uma formação superior aumenta as chances de inserção no mercado, e ter um trabalho decente é uma condição fundamental para a superação da pobreza, a redução das desigualdades sociais, a garantia da governabilidade democrática e o desenvolvimento sustentável (PIZZO, 2013).

Itens como transporte, residência, alimentação, xerox, livros, cultura e esporte são necessidades presentes na vida universitária, e a falta de condição para supri-los pode comprometer a formação acadêmica dos estudantes. Dessa forma, segundo Araújo et al. (2011), o acesso dos estudantes ao ensino superior sem contemplar possibilidades de permanência e conclusão dos cursos de graduação pode gerar altos índices de evasão que acabam por desestruturar cursos, frustrar expectativas dos envolvidos e da própria sociedade para com a universidade.

Kowarick (2003) ressalta que a extrema vulnerabilidade é de responsabilidade do Estado, considerando ser função da ação estatal combater a assim chamada exclusão social e econômica.

Em tal contexto, surge a Assistência Estudantil, que se trata de uma política pública de educação superior estruturada que visa responder às demandas dos estudantes em situação de vulnerabilidade, que estão tendo sua participação ampliada no ensino superior público brasileiro, na perspectiva de inclusão social, produção de conhecimento, melhoria do desempenho acadêmico e qualidade de vida (ASSIS et al., 2013).

Esta pesquisa foi norteada na seguinte questão: quais medidas de assistência estudantil foram adotadas nas universidades federais da Região Norte do Brasil para enfrentamento da pandemia do novo coronavírus (Covid-19),? 
O objetivo da pesquisa foi verificar as ações de assistência estudantil desenvolvidas pelas universidades da Região Norte do Brasil durante a pandemia, no período de março a outubro de 2020.

\section{MATERIAIS E METODOS}

De acordo com os objetivos propostos, a pesquisa foi realizada através de um estudo descritivo de abordagem qualitativa, utilizando a pesquisa documental como forma de coleta de dados.

O universo da pesquisa foi as universidades federais da Região Norte do Brasil, sendo elas: Universidade Federal do Acre (UFAC), Universidade Federal do Amapá (UNIFAP), Universidade Federal do Amazonas (UFAM), Universidade Federal do Pará (UFPA), Universidade Federal do Oeste do Pará (UFOPA), Universidade Federal Rural da Amazônia (UFRA), Universidade Federal do Sul e Sudeste do Pará (UNIFESSPA), Universidade Federal de Rondônia (UNIR), Universidade Federal de Roraima (UFRR) e Universidade Federal do Tocantins (UFT).

Ressalta-se que a Universidade Federal do Norte do Tocantins (UFNT) faz parte da lista de universidades federais da Região Norte do Brasil, mas ainda está no processo de transição de UFT para UFNT, dessa forma não há dados de assistência estudantil no portal. A UFNT foi criada em 2019 e instituída a partir do desmembramento dos câmpus de Araguaína e Tocantinópolis da UFT.

O objeto de estudo foi as ações de assistência estudantil no período de março a outubro de 2020, abrangendo do começo da pandemia até o mês de finalização deste artigo. Ressalta-se que a pandemia continua e não há previsão de retorno das aulas presenciais.

Quanto aos procedimentos de coleta de dados, o primeiro passo foi a realização de uma pesquisa documental nos portais das universidades. Segundo Vergara (2003, p. 48), a pesquisa documental "é realizada em documentos conservados no interior dos órgãos públicos e privados de qualquer natureza, ou com pessoas: registros, regulamentos, circulares, ofícios, memorandos, regimentos, fluxogramas, organogramas e outros". Esse meio de coleta de dados foi usado no sentido de reconstruir as ações de assistência estudantil desenvolvidas nas universidades pesquisadas no período da pandemia.

Buscaram-se informações nos portais das instituições que dessem visibilidade ao que foi oferecido aos estudantes. Os dados foram copilados por meio de notícias, editais, relatórios e pesquisas. 
Após a coleta de dados, foi realizada a tabulação, que segundo Vieira (2012), consiste em trabalhar os dados a fim de obter um retrato que possa demonstrar a realidade observável. Os dados foram organizados em um quadro e foram feitas a interpretação e a discussão dos resultados da pesquisa.

\section{RESULTADOS E DISCUSSÃO}

\section{Covid-19 e as aulas nas universidades federais}

Em março de 2020, a maioria das universidades federais suspendeu as aulas considerando o agravamento da pandemia causada pela Covid-19 em todo o território nacional e o Decreto Legislativo ํㅡ 6, de 20 de março de 2020, que reconheceu estado de calamidade pública no Brasil. Posteriormente, as instituições precisaram suspender o calendário acadêmico do primeiro semestre letivo de 2020.

Para amenizar os prejuízos causados pela pandemia de Covid-19, o Ministério da Educação (MEC) autorizou a substituição de disciplinas presenciais por aulas que utilizem meios e tecnologias de informação e comunicação em cursos que estão em andamento.

O problema é que, inicialmente, as universidades se depararam com a impossibilidade de oferecer aulas aos estudantes de graduação de forma remota. Verificou-se que, na atual conjuntura, não é possível garantir os princípios de igualdade, equidade e de inclusão nos processos de ensino-aprendizagem. Notou-se que os estudantes não possuem as mesmas condições tecnológicas de acesso às aulas online e as instituições não dispõem de infraestrutura e metodologia necessárias, uma vez que não ofertavam, até o momento, a modalidade de ensino à distância (EaD).

A partir do segundo semestre de 2020, a maioria das universidades aprovou, em caráter excepcional e temporário, o Ensino Remoto Emergencial (ERE), alternativamente às atividades presenciais de ensino. De acordo com o MEC, há previsões para o encerramento do ano letivo de 2020 nas universidades federais até maio de 2021.

O Quadro 1 ilustra o cronograma das universidades da Região Norte do Brasil, mostrando quando as aulas e os calendários acadêmicos de 2020.1 foram suspensos, além do Período Letivo Emergencial (PLE). 


\begin{tabular}{|c|c|c|c|c|}
\hline Universidades & $\begin{array}{l}\mathscr{D} \\
\frac{0}{0} \\
\frac{\pi}{0} \\
: \frac{0}{2}\end{array}$ & $\begin{array}{l}\text { Suspensão } \\
\text { das aulas } \\
\text { presenciais }\end{array}$ & $\begin{array}{c}\text { Suspensão do } \\
\text { Calendário } \\
\text { Acadêmico } \\
2020\end{array}$ & Período Letivo Emergencial (PLE) 2020.1 \\
\hline UFAC & & 17 de março & 30 de março & 26 de outubro a 28 de janeiro de 2021 \\
\hline UNIFAP & & 16 de março & 30 de março & 3 de novembro a 16 de janeiro de 2021 \\
\hline UFAM & & 13 de março & 31 de março & 8 de setembro a 14 de dezembro \\
\hline UFPA & & 19 de março & 22 de maio & 14 de setembro a 28 de fevereiro de 2021 \\
\hline UFOPA & & 19 de março & 3 de abril & 17 de agosto e 3 de outubro de 2020 \\
\hline UFRA & & 19 de março & 18 de maio & 10 de setembro a 14 de novembro \\
\hline UNIFESSPA & & 19 de março & 29 de abril & 15 de setembro a 22 de dezembro \\
\hline UNIR & & 20 de março & 20 de março & 27 de setembro a 18 de dezembro \\
\hline UFRR & & 17 de março & 21 de março & 8 de setembro a 19 de dezembro \\
\hline UFT & & 16 de março & 31 de março & 13 de outubro a 19 de dezembro \\
\hline
\end{tabular}

Fonte: Elaborado pelos autores (2020).

O ensino remoto prevê o desenvolvimento de atividades acadêmicas síncronas e/ou assíncronas. Entre os itens que serão utilizados para o Ensino Remoto Emergencial estão: salas de webconferências; videoaulas exibidas ao vivo ou gravadas; conteúdos em diferentes linguagens e formatos; correio eletrônico; sites de redes sociais; aplicativos de mensagens instantâneas como o WhatsApp e Telegram.

Além disso, caberá às instâncias colegiadas e coordenações de curso decidir quais componentes curriculares podem ser adaptados para a oferta no período letivo emergencial. A adesão é facultada, tanto para os docentes quanto para os discentes, sendo que os estudantes não terão prejuízos acadêmicos caso não possam cursar ou não obtenham sucesso na realização da disciplina.

A UFRR, inicialmente, não suspendeu o calendário acadêmico, a universidade instituiu um Regime Acadêmico Especial (RAE) para que as atividades fossem desenvolvidas pelos professores utilizando metodologias EaD, com os encontros sendo registrados virtualmente no Sistema de Integração de Gestão de Atividades Acadêmicas (SIGAA). Porém, no dia 21 de março, a universidade alterou esta resolução, visto que o método adotado sofreu críticas de estudantes, que alegavam não terem acesso à internet para realizar as atividades. Professores também questionaram a efetividade, já que o aproveitamento dos estudantes durante o período seria reduzido, além dos problemas na plataforma dificultarem o trabalho.

A UFOPA não retomou o calendário acadêmico para todos os estudantes, nesse segundo semestre a instituição resolveu ofertar o Período Letivo Especial (PLE) para os estudantes concluintes de diversos cursos. O objetivo foi possibilitar a conclusão da 
graduação dos estudantes que já integralizaram $80 \%$ dos seus respectivos cursos. Com o encerramento do PLE, que foi exclusivamente remoto, a UFOPA trabalha num cenário para uma retomada em janeiro de 2021. Mas a confirmação de uma data da retomada depende do planejamento das unidades acadêmicas, da avaliação das possibilidades de oferta, preparação de material para as aulas, entre outros encaminhamentos acadêmicos e administrativos que precisarão ser discutidos nos Conselhos Superiores da Universidade.

\section{Covid-19 e assistência estudantil nas universidades federais da região Norte do Brasil}

Em todas as universidades pesquisadas, foram criados grupos de trabalhos e/ou comissões sobre a Covid-19 para acompanhar a evolução do cenário epidemiológico e divulgar, a qualquer tempo, informações atualizadas sobre o assunto. Nesse contexto, a assistência estudantil demandou novos auxílios, tendo em vista o aprofundamento da situação de vulnerabilidade socioeconômica evidenciada pela pandemia de Covid-19.

O Quadro 2 explana os auxílios oferecidos pelas universidades federais da Região Norte do Brasil durante o período pesquisado, que foi de março a outubro de 2020.

Quadro 2 - Assistência estudantil nas universidades federais da Região Norte do Brasil durante o período da pandemia.

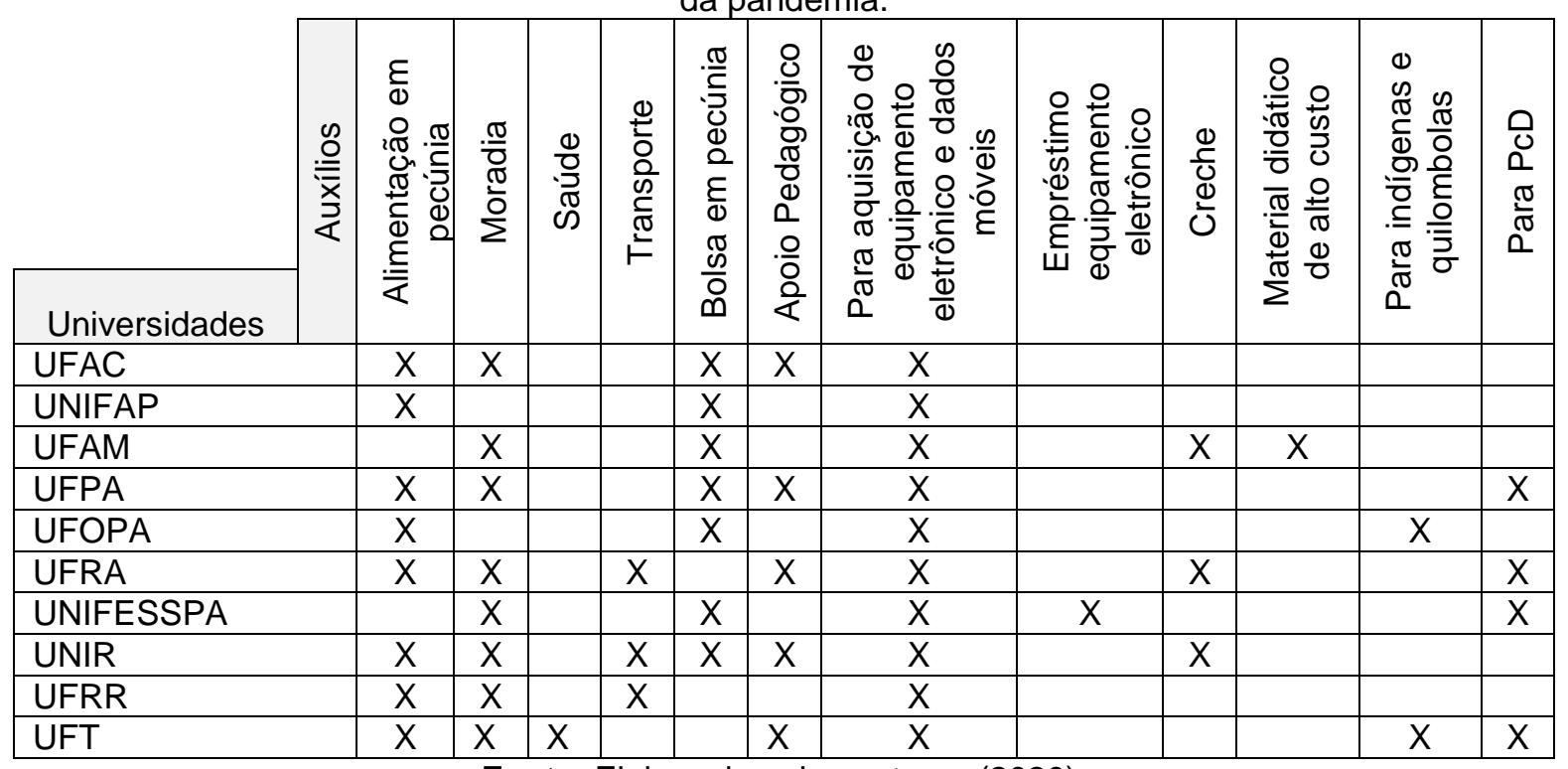

Fonte: Elaborado pelos autores (2020). 
Percebe-se que das dez universidades federais da Região Norte do Brasil, oito instituíram, de forma excepcional e temporária, o auxílio-alimentação emergencial em pecúnia para atender estudantes em condições de vulnerabilidade socioeconômica, com o objetivo de amenizar os efeitos decorrentes da suspensão das atividades dos Restaurantes Universitários (RUs), contribuindo para a manutenção e suporte de uma alimentação básica durante o período da pandemia. Como preconiza o PNAES, o objetivo é dar a garantia de igualdade de condições para a permanência com qualidade até a reabertura dos RUs, agindo preventivamente nas situações de retenção e evasão.

Os resultados mostram que oito das universidades pesquisadas ofereceram um auxílio específico para moradia, sendo ofertado através de vagas em imóveis (Casas dos Estudantes) e/ou de repasse mensal de auxílio financeiro para custeio de aluguel.

A UFT foi a única universidade que ofereceu auxílio específico para saúde durante o período da pandemia, um subsídio financeiro concedido aos estudantes que não conseguem custear parte das despesas com atendimento psicológico ou psiquiátrico, de acordo com a necessidade e gastos com medicação, a fim de que ele possa cumprir com as indicações de tratamento. Ressalta-se que esse auxílio é continuo na UFT desde 2016. Apenas a UFRA, a UNIR e a UFRR ofereceram auxílio-transporte durante o período pesquisado. Mas vale ressaltar que, por exemplo, a UNIFESSPA suspendeu o pagamento do auxílio-transporte de todos os editais vigentes enquanto durar a suspensão do calendário acadêmico, mas criou o pagamento de auxílio emergencial, em caráter excepcional, aos discentes que se encontravam no cadastro de reserva do último edital dos auxílios nas modalidades permanência e moradia.

Apesar de diferentes nomenclaturas, sete das dez universidades federais da Região Norte do Brasil oferecem alguma bolsa em pecúnia que pode ser usada para despesas de moradia, alimentação, saúde, transporte, entre outros. Esse auxílio ameniza o fato das universidades não ofertarem bolsas específicas para essas áreas.

Cinco das universidades lançaram editais relativos ao apoio pedagógico, sendo elas: UFAC, UFPA, UFRA, UNIR E UFT. Esse auxílio se refere a monitoria e tutoria para apoio aos estudantes com deficiência, transtornos globais do desenvolvimento e com altas habilidades/superdotação, além de tutoria para apoio aos estudantes portadores de deficiência intelectual, múltipla deficiência, surdez e transtorno do espectro autista.

Para ajudar os estudantes na retomada das atividades acadêmicas à distância, todas as universidades pesquisadas lançaram editais visando a inclusão digital para estudantes em vulnerabilidade socioeconômica, para garantir internet e um equipamento 
para os estudos. A criação desse tipo de auxílio demonstrou, conforme a literatura, que muitos estudantes não dispõem de recursos para suprirem suas necessidades básicas e as despesas típicas da vida universitária: livros, equipamentos de aprendizagem prática, acesso à informação, acesso à internet e participação em eventos acadêmicos e culturais (Fonaprace, 2019). Portanto, mesmo matriculados em instituições públicas, os estudantes têm gastos com transporte, alimentação, material didático, entre outros (ALMEIDA, 2011; ESTRADA; RADAELLI, 2017).

Em suporte às ações emergenciais ao ensino, pesquisa e assistência estudantil e apoio ao enfrentamento da pandemia de Covid-19, desde setembro o Governo Federal lançou o projeto "Alunos Conectados" com o objetivo de disponibilizar internet gratuita para os estudantes em situação de vulnerabilidade socioeconômica, de universidades e institutos federais. Para isso, foi firmado um convênio com a Rede Nacional de Ensino e Pesquisa (RNP) para a contratação de operadoras que forneçam planos de dados móveis. Ressalta-se que todas as universidades federais da Região Norte do Brasil aderiram ao programa.

Para complementar, todas as universidades pesquisadas ofereceram auxílio financeiro aos estudantes para a aquisição de equipamentos eletrônicos. No contexto da inclusão digital, a UFIFESSPA teve uma boa iniciativa: além da adesão ao projeto "Alunos Conectados", a instituição lançou o programa "Conecta" com a finalidade de selecionar estudantes em situação de vulnerabilidade socioeconômica para concessão do direito ao empréstimo de Chromebooks ${ }^{1}$ para acesso à internet e suporte à realização das atividades acadêmicas. Os estudantes selecionados têm direito ao empréstimo de Chromebook. Tal empréstimo foi realizado por meio do sistema de bibliotecas da UNIFESSPA (SIBI).

As ações de inclusão digital respeitam o compromisso das instituições com o acesso igualitário à educação, disposto na Constituição Federal.

A UFAM, a UFRA e a UNIR ofereceram auxílio-creche, que constitui um auxílio financeiro para estudantes que se encontrem em situação de vulnerabilidade socioeconômica e que necessitem do subsídio para custear despesas referentes à manutenção de creche ou similar ou cuidador para os/as filhos/as menores de seis anos de idade que não tenham com quem ficar durante o desenvolvimento de suas atividades acadêmicas.

\footnotetext{
${ }^{1}$ Aparelhos análogos a notebooks que funcionam totalmente baseados na web e permitem o uso de suas principais ferramentas off-line, ou seja, sem nenhuma conexão com a internet.
} 
A UFAM foi a única instituição que ofereceu auxílios para aquisição de material didático. O Auxílio Material Didático de Alto Custo (MATDAC) é de caráter pessoal e intransferível, destinado à compra de materiais de alto custo de uso individual que sejam obrigatórios e previstos nas disciplinas curriculares, de modo a proporcionar a realização das atividades práticas indispensáveis para o aproveitamento na etapa curricular dos cursos de Arquitetura e Urbanismo, Artes Visuais, Enfermagem, Música, Odontologia, Biotecnologia, Engenharia de Alimentos e Engenharia Química. Além disso, a UFAM ofereceu auxílio acadêmico destinado a custear parcialmente gastos com transporte público municipal urbano e material didático pedagógico de baixo custo.

Nota-se que a UFOPA e a UFT foram as únicas que lançaram editais para auxílios específicos durante a pandemia para estudantes indígenas e quilombolas ingressantes em 2020. Segundo a V Pesquisa Nacional de Perfil Socioeconômico e Cultural dos Graduandos das Universidades Federais, realizada pela Andifes e pelo Fonaprace, é notável a maior presença relativa de quilombolas na Região Norte, mais do que o dobro da proporção nacional. É também na Região Norte que se nota a maior proporção de indígenas, praticamente o triplo da proporção nacional, sejam eles aldeados ou não aldeados.

A UFPA, UFRA, UNIFESSPA e UFT lançaram editais com auxílios destinados a pessoas com deficiência, que envolvem um kit de tecnologia assistiva destinado a assistir discentes com deficiência (física, intelectual, auditiva, visual e transtornos do espectro autista), e que não possuem condições de arcar com custeio parcial ou integral de despesas com aquisição de tecnologia assistiva e/ou materiais acadêmicos específicos e/ou de instrução, inclusive para o ensino remoto, de uso individual, que acessibilizem o processo de educação do estudante com deficiência.

A tecnologia assistiva está relacionada, exclusivamente, a produtos, equipamentos e dispositivos de acessibilidade que objetivem promover a funcionalidade, relacionada à atividade e à participação da pessoa com deficiência, visando sua autonomia, independência, qualidade de vida e inclusão social (BRASIL, 2015).

Outras medidas foram tomadas pelas instituições, com por exemplo, em maio, a UFAC dispensou os estudantes contemplados nos editais de assistência estudantil, durante o período de suspensão das aulas, do cumprimento de contrapartidas relacionadas à frequência em aulas e/ou execução de atividades presenciais em ambientes acadêmicos ou administrativos. A universidade, ainda, prorrogou os auxílios 
até janeiro de 2021, podendo novamente ser prorrogados enquanto durar o período de pandemia da Covid-19.

A UFOPA destaca que houve a manutenção de todos os auxílios estudantis vigentes no PNAES e MEC durante a suspensão das atividades presenciais, mantendo o pagamento dos auxílios estudantis de todos os editais no âmbito da UFOPA e da bolsa do programa de Bolsa Permanência do MEC.

A UFRA lançou um processo de renovação de auxílios financeiros estudantis vinculados ao PNAES nas seguintes modalidades: alimentação, creche, moradia, manutenção, pedagógico e transporte, referente aos editais PNAES realizados até o ano de 2018.

A UNIR manteve o pagamento de todos os auxílios e bolsas do Programa de Assistência Estudantil conforme fluxo existente: auxílio-acadêmico; auxílio-moradia; auxílio-creche; auxílio-alimentação; auxílio-transporte/alimentação; auxílio emergencial; auxílio-transporte; Bolsa Monitoria Especial e Bolsa Tradutor/Intérprete de Libras.

A UFRR suspendeu todos os editais lançados em 2020 e resolveu prorrogar a vigência dos auxílios concedidos com os editais de 2019 até o retorno das atividades acadêmicas, considerando alterações no calendário acadêmico.

Na UFT, apesar da suspensão do calendário acadêmico, os auxílios de assistência estudantil foram mantidos durante a pandemia de Covid-19: auxílio-alimentação, auxíliomoradia, auxílio-saúde e auxílio apoio pedagógico. São 2.615 auxílios concedidos mensalmente aos estudantes com vulnerabilidade socioeconômica.

\section{CONSIDERAÇOEES FINAIS}

Em todas as universidades pesquisadas, foram criados grupos de trabalhos e/ou comissões sobre a Covid-19 para acompanhar a evolução do cenário epidemiológico e atuar, entre outras questões, na assistência estudantil.

Percebe-se que oito das universidades instituíram, de forma excepcional e temporária, o auxílio-alimentação emergencial em pecúnia até a reabertura dos Restaurantes Universitários (RUs), além de oferecerem um auxílio específico para moradia através de vagas nas Casas dos Estudantes e/ou de repasse mensal de auxílio financeiro para custeio de aluguel.

Das universidades pesquisadas, somente a UFT ofereceu auxílio específico para saúde durante o período da pandemia. E a UFRA, a UNIR e a UFRR ofereceram auxílio- 
transporte durante o período pesquisado, sendo que a UNIFESSPA suspendeu o pagamento do auxílio transporte de todos os editais vigentes enquanto durar a suspensão do calendário acadêmico, mas criou o pagamento de auxílio emergencial em caráter excepcional.

Notou-se que, apesar de diferentes nomenclaturas, sete universidades federais da Região Norte do Brasil oferecem alguma bolsa em pecúnia que pode ser usada para despesas de moradia, alimentação, saúde, transporte, entre outros. E cinco das universidades lançaram editais relativos ao apoio pedagógico, sendo elas: UFAC, UFPA, UFRA, UNIR E UFT.

Um fato importante foi que durante o período da pandemia, a assistência estudantil demandou novos auxílios na área de inclusão digital. Para tanto, todas as universidades da Região Norte do Brasil aderiram ao projeto do Governo Federal "Alunos Conectados", que disponibilizou internet gratuita para os estudantes em situação de vulnerabilidade socioeconômica. As universidades pesquisadas ofereceram, ainda, auxílio financeiro aos estudantes para aquisição de equipamentos eletrônicos, e a UNIFESSPA lançou o programa "Conecta", com a finalidade de selecionar estudantes em situação de vulnerabilidade socioeconômica para concessão do direito ao empréstimo de Chromebooks para acesso à internet e suporte à realização das atividades acadêmicas.

A UFAM, a UFRA e a UNIR ofereceram auxílio-creche, e a UFAM foi a única instituição que ofereceu auxílios para aquisição de material didático. Notou-se que a UFOPA e a UFT foram as únicas que lançaram editais para auxílios específicos durante a pandemia para estudantes indígenas e quilombolas ingressantes em 2020. E a UFPA, UFRA, UNIFESSPA e UFT lançaram editais com auxílios destinados a pessoas com deficiência.

Outras medidas foram tomadas pelas instituições, como por exemplo, a UFAC dispensou os estudantes contemplados nos editais de assistência estudantil durante o período de suspensão das aulas e do cumprimento de contrapartidas. Em suma, percebeu-se que as universidades da Região Norte do Brasil mantiveram e/ou prorrogaram os auxílios da assistência estudantil durante o período de pandemia da Covid-19.

Portanto, identificaram-se diversas estratégias que representaram, efetivamente, avanços significativos no caminho de dirimir desigualdades históricas e equalizar oportunidades para os estudantes de grupos menos favorecidos permanecerem e concluírem os cursos superiores nas universidades da Região Norte do Brasil. 
É oportuno destacar que o tema "política pública de assistência estudantil no ensino superior" tornou-se ainda mais importante no contexto atual da pandemia de Covid-19, principalmente como ferramenta para mitigar as desigualdades socioeconômicas e a ineficiência das demais políticas públicas e de proteção social, como por exemplo, as políticas de emprego, de saúde e habitação. Assim, sugere-se que a temática seja pesquisada nas demais regiões do Brasil pelo período que a pandemia perdurar, utilizando, inclusive, outros meios de coleta de dados.

\section{REFERÉNCIAS}

ALMEIDA, M. L. Universidade e desigualdade social: a difícil superação da falsa disjuntiva entre teoria e prática. Espacio abierto, v. 20, n. 2, p. 267-287, abr./jun. 2011.

ARAÚJO, M.A. M.; ALMEIDA, L. L.; LOURO, D. W.; DEL-MASSO, M. C. S. O Impacto da Política de Permanência Estudantil na UNESP: a percepção do aluno bolsista. Revista Ciência e Extensão, v. 7, n. 2, p. 16-28, jul./dez. 2011.

ASSIS, A. C. L.; SANABIO, M. T.; MAGALDI, C. A.; MACHADO, C. S. As Políticas de Assistência Estudantil: experiências comparadas em universidades públicas brasileiras. Revista GUAL, v. 6, n. 4, p. 125-146, Edição Especial 2013.

BAQUEIRO, D. F. A.; TENÓRIO, R. M. Política de Assistência Estudantil: contribuições na promoção da Equidade e Eficácia no ensino. Disponível em: http://www.equidade.faced.ufba.br/sites/equidade.oe.faced.ufba.br/files/politica de assist encia estudatil e equidade - diciola figueiredo e robinson tenorio.pdf Acesso em: 09 fev. 2015.

CARVAlHO, S. C. S. Avaliação da eficácia da Política Pública de Assistência Estudantil na Universidade Federal de Lavras. 2013. 130 p. (Dissertação de mestrado) - Universidade Federal de Lavras, Lavras, MG, 2013.

BRASIL. Decreto legislativo n. 6 (2020). Reconhece, para os fins do art. 65 da Lei Complementar no 101, de 4 de maio de 2000, a ocorrência do estado de calamidade pública. Brasília, DF: Congresso Nacional, 2020.

BRASIL. Decreto n. 7.234 (2010). Dispõe sobre o Programa Nacional de Assistência Estudantil - PNAES. Brasília, DF: Presidência da República, 2010.

ESTRADA, A. A.; RADAELLI, A. A política de assistência estudantil em uma universidade pública: a perspectiva estudantil. Revista online de Política e Gestão Educacional, v. 16, p. 32-47, 2017.

FARIA, J. P. Extensão Universitária como mecanismo de desenvolvimento educacional e social no Brasil. Fragmentos de cultura, v. 25, n. 1, p. 75-82, jan./mar. 2015. 
FONAPRACE. V Pesquisa Nacional de Perfil Socioeconômico e Cultural dos Graduandos das Universidades Federais. Brasília: ANDIFES, 2019.

KOWALSKI, A. V. Os (des)caminhos da Política de Assistência Estudantil e o desafio na garantia de direitos. 2012. 180 p. (Tese de Doutorado) - Pontifícia Universidade Católica do Rio Grande do Sul, Porto Alegre, RS, 2012.

KOWARICK, L. Sobre a vulnerabilidade socioeconômica e civil. RBCS, v. 18, n. 51, p. 61 85, fev. 2003.

BRASIL. Lei n. 13.146 (2015). Institui a Lei Brasileira de Inclusão da Pessoa com Deficiência (Estatuto da Pessoa com Deficiência). Brasília, DF: Presidência da República, 2015.

PIZZO, A. A esfera do trabalho como lócus de justiça social. Revista Brasileira de Desenvolvimento Regional, v. 1, n.1, p.5-31, outono 2013.

RADO, S. C.; BONETI, L. W. A juventude em condições de vulnerabilidade social e as políticas de acesso à educação. In: CONGRESSO NACIONAL DE EDUCAÇÃO, 9, 2009, Curitiba. Anais [...]. Paraná, 2009, p. 3607-3618.

UNIVERSIDADE FEDERAL DE RONDÔNIA [UNIR]. Disponível em: http://www.procea.unir.br/ Acesso em: 31 out. 2020.

UNIVERSIDADE FEDERAL DE RORAIMA [UFRR]. Disponível em: http://prae.ufr..br/index.php/downloads/category/34-2020 Acesso em: 31 out. 2020.

UNIVERSIDADE FEDERAL DO ACRE [UFAC]. Disponível em: http://www2.ufac.br/editais/proaes/proaes Acesso em: 31 out. 2020.

UNIVERSIDADE FEDERAL DO AMAPÁ [UNIFAP]. Disponível em : https://www2.unifap.br/proeac/editais/ Acesso em: 31 out. 2020.

UNIVERSIDADE FEDERAL DO AMAZONAS [UFAM]. Disponível em: https://progesp.ufam.edu.br/publicacoes-e-noticias/634-editais-auxilios-estudantis2020.html Acesso em: 31 out. 2020.

UNIVERSIDADE FEDERAL DO OESTE DO PARÁ [UFOPA]. Disponível em: http://www.ufopa.edu.br/media/file/site/proges/documentos/2020/554cf34893165c3dc0cbb 1ba52ec6b33.pdf Acesso em: 31 out. 2020.

UNIVERSIDADE FEDERAL DO OESTE DO PARÁ [UFOPA]. Disponível em: http://www.ufopa.edu.br/proges/documentos-2/editais-abertos-1/2020/ Acesso em: 31 out. 2020.

UNIVERSIDADE FEDERAL DO PARÁ [UFPA]. Disponível em: http://sigaest.ufpa.br/sigaest/editais.php Acesso em: 31 out. 2020. 
UNIVERSIDADE FEDERAL DO SUL E SUDESTE DO PARÁ [UNIFESSPA]. Disponível em: https://www.unifesspa.edu.br/categoria-de-editais/auxilios Acesso em: 31 out. 2020.

UNIVERSIDADE FEDERAL DO TOCANTINS [UFT]. (2020). Disponível em: https://ww2.uft.edu.br/proest Acesso em: 31 out. 2020.

UNIVERSIDADE FEDERAL RURAL DO AMAZONAS [UFRA]. Disponível em: https://proaes.ufra.edu.br/index.php?option=com content\&view=article\&id=149\&/temid $=27$ 8 Acesso em: 31 out. 2020.

VERGARA, S. C. Projetos e Relatórios de Pesquisa em Administração. 3 ed. São Paulo: Atlas., 2003.

VIEIRA, J. G. S. Metodologia de Pesquisa Científica na Prática. Curitiba: Fael, 2012. 